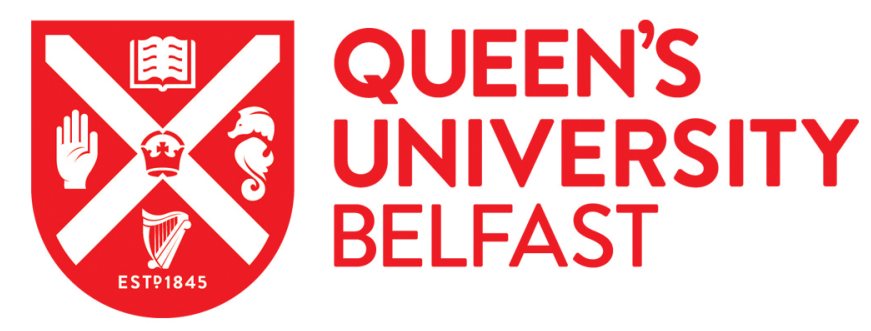

\title{
Stress and distress in parents of neonates admitted to the neonatal intensive care unit for cardiac surgery
}

Diffin, J., Spence, K., Naranian, T., Badawi, N., \& Johnston, L. (2016). Stress and distress in parents of neonates admitted to the neonatal intensive care unit for cardiac surgery. Early human development, 103, 101107. https://doi.org/10.1016/j.earlhumdev.2016.08.002

\section{Published in:}

Early human development

\section{Document Version:}

Peer reviewed version

Queen's University Belfast - Research Portal:

Link to publication record in Queen's University Belfast Research Portal

\section{Publisher rights}

(C) 2016 Elsevier Ireland Ltd. All rights reserved. This manuscript version is made available under the CC-BY-NC-ND 4.0 license http://creativecommons.org/licenses/by-nc-nd/4.0/which permits distribution and reproduction for non-commercial purposes, provided the author and source are cited.

\section{General rights}

Copyright for the publications made accessible via the Queen's University Belfast Research Portal is retained by the author(s) and / or other copyright owners and it is a condition of accessing these publications that users recognise and abide by the legal requirements associated with these rights.

Take down policy

The Research Portal is Queen's institutional repository that provides access to Queen's research output. Every effort has been made to ensure that content in the Research Portal does not infringe any person's rights, or applicable UK laws. If you discover content in the Research Portal that you believe breaches copyright or violates any law, please contact openaccess@qub.ac.uk. 
STRESS AND DISTRESS IN PARENTS OF NEONATES ADMITTED TO THE NEONATAL INTENSIVE CARE UNIT FOR CARDIAC SURGERY.

\begin{abstract}
Background: Parents of infants admitted to the Neonatal Intensive Care Unit (NICU) are at risk of psychological distress and NICU-related stress. However, parents of infants admitted to NICU for cardiac surgery are an under-researched population.
\end{abstract}

Aims: Identify levels of NICU-related stress, and levels of psychological distress, reported by parents of infants admitted to the NICU for cardiac surgery.

Study Design: Observational study.

Subjects: 69 parents of infants admitted to the NICU for cardiac surgery (cardiac group) and 142 parents of healthy infants (control group).

Outcome Measures: Questionnaire packs provided to parents prior to discharge (time-point 1), and at six and 12 months corrected age included: Hospital Anxiety and Depression Scale, Coping Inventory for Stressful Situations, and Family Support Scale. The Parental Stressor Scale:NICU was administered to the cardiac group at time-point 1.

Results: The cardiac group reported (i) that parental role alteration was the most stressful aspect of the NICU and (ii) higher scores for anxiety and depression than the control group at all three time-points, with the highest levels reported during the NICU stay. Correlation analyses indicated (i) stress associated with the sights and sounds of the NICU, and the appearance and behaviour of the infant in the NICU, had a significant positive association with anxiety and depression, and (ii) a significant negative relationship between anxiety and task-focused coping. 
Conclusions: An individualised parent-targeted intervention aimed at reducing stress associated with the NICU and enhancing task-focused coping style may help to reduce levels of anxiety and depression within this group of parents.

Keywords: cardiac surgery; neonates; NICU; parent; psychological distress; stress 


\section{BACKGROUND}

New parents are at risk of experiencing psychological distress, including anxiety and depression [1-2]. High levels of distress may disrupt normal interactions between the parent and infant, interfere with the parent-infant attachment process [3-5], and impact negatively upon the infant's intellectual and behavioural development, educational attainment, and mental health [6-8]. It is therefore feasible that parents of infants admitted to the Neonatal Intensive Care Unit (NICU) may be at risk of additional distress. It has been reported that 40$50 \%$ of parents have reported high levels of psychological distress during the hospitalisation of their infant in the NICU, or within the first few weeks after discharge [9-12]. Studies have shown that variables such as parental coping style, social support, and parental age are associated with psychological distress in parents of infants admitted to the NICU [13-16]. The NICU environment may also be stress- inducing for parents, including the sights of equipment, bright lights, and unfamiliar sounds, the infant's physical appearance, and the interruption to the normal parenting role [17-21]. High levels of stress associated with the NICU environment have also been reported to be associated with higher levels of parental psychological distress [22-23].

To date, a paucity of studies have assessed the NICU-related stress experienced by parents of infants with complex medical and/or surgical conditions; including cardiac surgery [24-26]. This is despite reports that the birth prevalence of congenital heart disease (CHD) worldwide is now eight in every 1000 live births, with up to 50\% of such children requiring surgery [27, 28]. Studies have tended to focus on more general levels of parental stress within this population [29]. Furthermore, few studies have examined psychological distress reported by mothers and fathers of infants admitted to the NICU for cardiac surgery, or investigated 
reasons why some parents report higher levels of distress than others,. Such studies have also included children from a wide range of age groups [30-33]. Elevated levels of psychological distress have been reported in one-third of mothers of infants', and almost one-fifth of fathers with congenital heart disease (CHD) in the first few months following the birth [32]. A recent study also reported that $14 \%$ of parents of infants with CHD had borderline state anxiety scores, and 5\% of parents had significant levels of both state and trait anxiety at the time of hospital discharge [34]. Mothers of infants with severe CHD have also been reported to have significantly higher levels of psychological distress than a control group of mothers of healthy infants at 6, 18, and 36 months postpartum [35-36]. Overall, the evidence suggests that parents of infants admitted to the NICU are at risk of psychological distress. However, parents of infants with CHD who have surgery in the neonatal period remain an underresearched population.

This study reports data from a larger project which was guided by the The Double ABCX Model of Family Adjustment and Adaptation [37] and focuses on mothers and fathers of infants admitted to the NICU for cardiac surgery.

This study aimed to investigate the following:

(1) The level of stress associated with the NICU environment reported by mothers and fathers of infants undergoing cardiac surgery. 
(2) The levels of psychological distress reported by the parents during their infant's admission to the NICU for cardiac surgery, and over time, in comparison to parents of healthy infants.

(3) The association between coping style, social support, NICU-related stress, parent age, and psychological distress, in parents of infants admitted to the NICU for cardiac surgery. 


\section{METHODS}

\section{Participants}

The sample was recruited between $7^{\text {th }}$ March 2010 and 30 ${ }^{\text {th }}$ June 2011 from the Grace Centre for Newborn Care at The Children's Hospital at Westmead (CHW), New South Wales, Australia. The inclusion criteria for the surgical group were parents of infants born $>30$ weeks gestation admitted to the NICU with a diagnosis of a congenital anomaly requiring neonatal surgery. This study reports on a sub-set of data on parents of babies admitted to the CHW for cardiac surgery which was collected as part of a larger multi-site project. Control participants were recruited from the co-located maternity unit at Westmead Hospital as this was the same geographical area serving a similar population. The inclusion criteria were parents of infants born greater than 37 weeks gestation with no medical or health concerns. Parents were excluded if they were: (i) under the age of 16, (ii) unable to consent for themselves, (iii) non-English speaking, (iv) from inter-state or an international country. A flow diagram describing the number of participants within the study at each time-point is presented in Figure 1.

\section{Procedure}

For the cardiac group, readiness for recruitment was determined by the clinical stability of the infant, and in collaboration with the NICU clinical team. A suitable time post- initial surgery, and prior to discharge, was chosen for time-point 1 data collection. For the control group, recruitment and time-point 1 data collection occurred during admission to the maternity unit and questionnaires were completed within four weeks of discharge. Self-completion questionnaire packs at time-point 1 included: a demographic questionnaire, the Hospital Anxiety and Depression Scale (HADS) [38], the Coping Inventory for Stressful Situations 
(CISS) [39], and the Family Support Scale (FSS) [40]. The Parental Stressor Scale:NICU (PSS:NICU) [41] was only administered to the cardiac group. Medical notes were accessed to obtain infant characteristics. Postal questionnaire packs were administered when the infant was six months (demographic questionnaire, HADS, CISS and FSS), and 12 months corrected age (demographic questionnaire, HADS and FSS).

\section{Instruments}

The PSS:NICU [41] is used to measure parents’ perceptions of stressors arising from the physical and psychosocial environment of the NICU (administered to parents in the cardiac group only). The Metric 2 scoring procedure (Overall Stress level) was used in the current study [41]. There are three subscales within this questionnaire for which scores can be calculated. The 'Appearance and Behaviour' subscale assesses aspects of the baby’s appearance which may cause stress for the parent, such as the whether they appear to be cold and behaviours such as whether they are crying. The 'Sights and Sounds' subscale assesses how aspects of the NICU such as the sights and sounds of monitors and seeing other sick infants in the room may cause the parent to experience stress. The 'Parental Role and Relationship’ subscale assesses how experiences such as not being able to hold their baby, and not being able to see the child when the parents wanted, may cause stress for the parents. The score for each subscale ranges from 1 to 5 and from 34 to 170 for Overall Stress. Higher scores are indicative of higher levels of NICU-related stress.

The HADS [38] was used as a screening measure in order to assess the levels of self-reported depression and anxiety in the parents. Scores range from 0 to 21 with higher scores indicating higher levels of anxiety or depression. Scores can also be categorised as follows: 'normal' 0- 
7, ‘mild’ 8-10, ‘moderate’ 11-14 and ‘severe’ 15-21. The CISS [39] was used to assess coping style. Coping styles are evaluated on separate subscales and include task-focused coping, emotion-focused coping, and avoidance coping. Scores for each subscale range from 16 to 80 with higher scores indicative of a greater degree of coping activity within that dimension. Social support was assessed using the FSS [40] which is a measure of how helpful different sources of support have been for families. The Total FSS Score ranges from 0 to 90 with higher scores indicative of higher perceptions of helpfulness of support. Reliability analyses were conducted for each measure used within the current study and results were satisfactory, indicating they were appropriate for use.

\section{Statistical Analyses}

Differences in parental demographic characteristics between mothers and fathers in each group at time-point 1 were compared using independent $t$-tests for normally distributed variables, Kruskal-Wallis for non-normal continuous variables, and Chi-square for categorical variables (or Fisher's Exact Test if expected frequencies were less than five). Differences in demographic characteristics and questionnaire responses at time-point 1 were compared for those who responded at each time-point in the study and those who responded at time-point 1 only.

Due to the small sample size, a bootstrap technique was performed on the data and confidence intervals were calculated for the mean scores on each measure [42]. A MANOVA (Multivariate Analysis of Variance) to investigate any differences between PSS:NICU scores for mothers and fathers. Changes in anxiety and depression scores over time between parents in each group (cardiac and control) were analysed using two-way repeated measures 
ANOVA's. All assumptions were explored prior to the analyses. Any variable which the existing literature suggested may have confounded the results was considered for inclusion as a covariate. Pearson correlation analyses with parents in the cardiac group examined the association between and psychological distress during their infants' admission to the NICU and parental age, coping style, social support, and NICU-related stress. Analyses were conducted using SPSS (Statistical Package for Social Sciences, Version 17, SPSS Inc, Illinois, USA). 


\section{RESULTS}

\section{Parent Characteristics}

A significant difference in parental age between fathers in the cardiac and control groups, and a significant difference in education level and cultural identity between parents in each group was observed (Table 1). Within the cardiac group, those who responded at time-point 1 only reported higher scores on the 'Appearance and Behaviour' subscale in comparison to those who responded at each time-point $[t=3.13, \mathrm{df}=65, p=.003]$ with a mean difference of 0.72 , 95\% CI $(0.26,1.18)$. However, no other significant differences in demographic characteristics or time-point 1 scores were observed between those who responded at each time-point and those who responded at time-point 1 only in either group (analysis not displayed).

[INSERT TABLE 1 HERE] 


\section{Infant Characteristics}

There were 13 male and 24 female babies with congenital heart disease (CHD), and 36 male and 44 female babies in the control group (infant data for one baby was missing). The mean length of stay in the NICU for the babies in the cardiac group was 23 (SD 6) days. The mean gestational age for the cardiac group was 37 (SD 7) weeks and for the control group was 38 (SD 8) weeks. Within the cardiac group, 32.4\% (12/37) had transposition of the great arteries, 13.5\% $(n=5)$ had hypoplastic left heart syndrome, $24.5 \%(n=9)$ had coarctation of the aorta, and 43\% (n=16) were diagnosed with 'complex' cardiac conditions. This 'complex' group comprised nine different conditions, all of which required surgery in the first week following birth (see supplemental file 1 for a full overview).

\section{Parental Stress Associated with the Neonatal Intensive Care Environment}

Mothers had a higher mean score than fathers on the 'Parental Role and Relationship', and 'Sights and Sounds' subscales of the PSS:NICU (Table 2). There was a significant main effect of Parent Role (Mother/Father) on Overall PSS:NICU scores, $F(4,63)=4.24, p=0.004$; Pillai's Trace $=0.21$. There was a significant effect of Parent Role (Mother/Father) on the 'Parental Role and Relationship' subscale, $F(1,69)=9.98$, $p=0.002$; mothers' scores were significantly higher than fathers' scores $[t=-3.19, \mathrm{df}=69, p=0.002]$ with a mean difference of $-0.60,95 \%$ CI (-0.97, -0.22).

There was no significant effect of Parent Role (Mother/Father) on the 'Appearance and Behaviour' subscale, $F(1,69)=0.33, p=0.57$, or the 'Sights and Sounds', $F(1,69)=0.001, p=$ 0.98 subscale. 
[INSERT TABLE 2 HERE] 


\section{Parental Distress During and After Discharge from the NICU}

Means scores for anxiety and depression were higher for parents in the cardiac group in comparison to the control group, at all three time-points in the study (Table 3). Furthermore, a higher percentage of parents in the cardiac had moderate or severe levels of anxiety depression at time-point 1 in comparison to parents in the control group (See supplemental file 2). Interestingly, at 6 months the percentage of parents with moderate or severe levels of anxiety and depression were more similar within each group but by 12 months, a higher percentage of parents in the cardiac group had moderate or severe levels of anxiety.

Whilst significant differences in cultural identity and education level and age were observed between groups, checks on correlations among covariates indicated it was only appropriate to include parent education level as a covariate within the analysis for anxiety levels over time as the other variables considered for inclusion did not have any cause and effect relationship with the dependent variables (anxiety and depression scores). After controlling for parent education level, there was a significant effect of time on anxiety scores, $F(2,224)=6.73$, $p=0.001, \eta^{2}=0.06$. Scores at time-point 1 were significantly higher than at six months, $F(1,112)=8.53, p=0.004, \eta^{2}=0.07$, but did not differ significantly between six and 12 months, $F(1,112)=0.005, p=0.95, \eta^{2}=0$, indicating that overall, scores for anxiety decreased over time.

Anxiety scores differed significantly between the cardiac and control groups $F(2,224)=$ 11.37, $p<001, \eta^{2=} 0.90$. A significant interaction was observed when comparing anxiety scores at time-point 1 and six months, $F(1,112)=17.13, p<0.001, \eta^{2}=0.14$, with anxiety scores decreasing between time-point 1 and six months for parents in the cardiac group whilst 
remaining more stable for parents in the control group. However, no significant interaction was identified when comparing time-point 1 and 12 month anxiety scores, $F(1,112)=1.55$, $p=0.22, \eta^{2}=0.01$, indicating that the differences in anxiety scores between control and cardiac group parents were no longer evident at 12 months.

There was no significant effect of time on scores for depression, $F(2,242)=2.42, p=0.09, \eta^{2}$ $=0.02$. However, depression scores differed significantly between the cardiac and control groups. $F(2,242)=8.77, p<.001, \eta^{2}=0.07$. A significant Depression by Group interaction was observed when comparing depression scores at time-point 1 with those at six months, $F(1,121)=11.26, p=0.001, \eta^{2}=0.09$. However, there was no significant interaction when comparing depression scores at six and 12 months, $F(1,121)=0.07, p=0.79, \eta^{2}=0.001$, indicating that the differences in depression scores between control and cardiac group parents were no longer evident at 12 months.

[INSERT TABLE 3 HERE] 


\section{Social Support and Coping Style}

Fathers within each group reported higher levels of social support than mothers at time-point 1. Mothers and fathers within the cardiac group reported higher levels of social support than mothers and fathers in the control group at the 12 month follow-up (Table 4). Mothers and fathers in the control group had higher levels of task-focused, and avoidance coping at each time-point, in comparison to mothers and fathers in the cardiac group (Table 4). Fathers in the cardiac group had the highest levels of emotion-focused coping activity at both time-point 1 and 12 months.

[INSERT TABLE 4 HERE] 


\section{Variables associated with psychological distress for parents within the cardiac group}

For parents within the cardiac group, the highest levels of psychological distress were reported during the infant's stay in the NICU. Stress associated with the sights and sounds of the NICU had a significant, positive association with both depression, $r(69)=0.27, p=0.03$, and anxiety $r(69)=0.40, p=0.001$. Stress associated with the appearance and behaviour of the infant in the NICU also had a significant, positive association with both depression, $r(67)=0.26, p=0.03$, and anxiety; $r(67)=0.31, p=0.01$. There was also a significant negative association between task-focused coping style and anxiety, $r(70)=-0.25, p=0.04$, indicating that as levels of task-focused coping increased, anxiety scores decreased (see supplementary file 3 for correlation matrix). 


\section{DISCUSSION}

Parenting a baby who requires hospitalisation and surgical intervention in the first few days or weeks following birth is stressful, with feelings of anxiety and depression potentially lasting long after the baby is discharged home. The results of the current study indicated that during the NICU stay, parents reported that the alteration to the parental role and relationship with their infant was the most stressful aspect for them, with mothers reporting higher levels of stress than fathers. These findings are consistent with previous studies [17-18]. Furthermore, levels of both depression and anxiety, as measured by the HADS [34], were highest during the NICU stay for parents in the cardiac group, and although those levels decreased over the time period of study, their reported anxiety and depression remained consistently higher in comparison to parents in the control group. Indeed, differences in levels of psychological distress between mothers of a baby with CHD and mothers of a healthy infant have also been reported previously [29]. The findings are also similar to other studies of parents of infants admitted to the NICU, where levels of psychological distress were higher during admission and decreased over time [10]. Transition from hospital to home is also a recognised time of additional stress for parents and higher levels of anxiety have also been previously reported in another study of parents with CHD at the time of hospital discharge [30]. Such disruptions to the parental role, and parental feelings of anxiety and depression, may potentially impact negatively on the attachment process which in turn may have implications for the infant's later development and therefore this is a vitally important issue to address [3-8].

Differences in coping style were observed between each group. Parents in the cardiac group reported higher levels emotion-focused coping, and lower levels of task-focused and 
avoidance coping activity, than parents in the control group. The CISS is not intended to be a situation-specific measure of coping, however, it may be that parents in the cardiac group were referring to the strategies they were specifically using during the stressful situation they were currently experiencing when answering these questions rather than their coping activities in general. Parents in the cardiac group may also have been constrained by situational factors as a result of spending prolonged periods of time in the hospital environment, and avoidance strategies such as distraction and avoidance of the situation, and task-focused coping strategies, may have been more affected by such constraints than emotional coping methods. However, differences in parental coping style between parents of children with autism and Down syndrome, and parents of normal developing children have been reported previously, suggesting that caring for a child with more complex needs may result in the utilisation of different coping strategies in comparison to parents of children without such needs [43-44]. Differences between mothers and fathers in the coping style they adopt have also been reported previously [45-46].

Stress associated with the NICU stay was associated with higher levels of anxiety and depression. A link between psychological distress and NICU-related stress has been reported previously in a study of mothers of preterm babies [14]. Parents with an infant admitted to the NICU for surgery may have experienced their baby undergoing a number of painful medical, and surgical procedures. A study which investigated mothers' perceptions of the pain experienced by their infant in the NICU found that seeing their infant undergo painful procedures, and an inability to protect their infant from pain, was stress inducing [47]. In contrast to previous findings [13], levels of social support were not significantly associated with either anxiety or depression in the current study. Task-focused coping was associated 
with lower levels of anxiety. These results support the findings from previous study which reported that greater use of task-focused coping strategies are predictive of lower levels of psychological distress for parents [15].

The main strengths of this study were the inclusion of both mothers and fathers, and the use of a control group consisting of parents of healthy babies. However, the control group of parents was not matched on any variables and parents in the cardiac group were younger, had lower levels of education, and were less likely to identify themselves as Australian. Parents with lower levels of education may have had a lower socio-economic status with fewer resources to help them, and different coping styles than parents with a higher level of education, which may have made them more vulnerable to experiencing distress [48-49]. There may also be a potential for cultural variations in reports of psychological distress, however given the small sample size this could not be examined explicitly within the current study. Furthermore, the majority of parents in this study were either married or cohabiting and therefore results cannot be generalised to single parent families. In addition, whilst the mean gestational age was similar for infants within each group, the CHD group did include some premature infants which may potentially have added some additional stress for parents. However, the small sample of parents in the cardiac group restricted what further statistical analyses could be performed. Unfortunately, it is not known if there were any differences in the time at which the survey pack at time-point 1 was completed between each group which may have impacted on the findings. Lastly, the drop-out rate for the control group was high despite numerous attempts to encourage participation in each stage of the study. 
This study has a number of implications for practice. As parents of infants admitted to the NICU for cardiac surgery are a unique population, practices should address the specific needs of such parents and their baby, rather than be generalised to the NICU population as a whole. Individualised interventions that focus on working with parents as partners in their baby's care, such as supporting the acquisition of task-focused coping skills to assist with the care of and interactions with their infant, may help to minimise stress associated with alterations to their parenting role, and help to reduce feelings of depression and anxiety. A reduction in feelings of anxiety and depression during their infant's admission to the NICU may subsequently reduce the risk of such distress in the longer-term. However, parents should also be directed to the appropriate sources of support after their baby has been discharged home such as their GP, child health nurse, or relevant parent support groups. Furthermore, healthcare professionals should use any follow-up appointment for the baby as an opportunity to explore any parental concerns and identify if further support is required.

In conclusion, this study provides important information relating to the stress and psychological distress that parents of a baby undergoing cardiac surgery may be at risk of in the short- and longer-term, and provides some insight into the coping strategies utilised by parents during the NICU stay. Such information is vital for the development of interventions, and policies, to help such parents in the future. This will ultimately be of direct impact to the optimal development, and well-being of children who have cardiac surgery in the neonatal period. 


\section{ACKNOWLEDGEMENTS}

We thank the parents who participated in this project, contributing their time and experiences. We acknowledge Susan Heath, Clinical Midwifery Consultant, High Risk Birth Unit, Westmead Hospital, Sydney, for her role in recruitment. We also acknowledge Jan Stewart, Grace Centre for Newborn Care, The Children’s Hospital at Westmead, Sydney, for her role in data management.

\section{CONTRIBUTION STATEMENT}

JD contributed to the data management, completed the data analyses, drafted and revised this manuscript, and is the corresponding author. KS contributed to the design of the study and as the lead investigator was responsible for the overall project management and recruitment. KS also contributed to the manuscript, critically reviewed, revised and approved the final submission. TN contributed to the content of the manuscript. NB contributed to the design and management of the study and critically reviewed, revised, and approved the final submission. LJ contributed to the design and management of the study, critically reviewed, revised and approved the final submission.

\section{FUNDING}

This project was funded by an Australian Research Council (ARC) Linkage Grant (LP0883457).

\section{ETHICAL APPROVAL}

Full ethical approval for this project was obtained from The Children’s Hospital at Westmead Human Research Ethics Committee (HREC reference: 10/CHW/7). 
CONFLICT OF INTEREST STATEMENT

None declared 


\section{REFERENCES}

[1] Parfit Y, Ayers S. Transition to parenthood and mental health in first-time parents. Infant Ment Health J 2014;35:263-273.

[2] Seymour M, Giallo R, Cooklin A, Dunning M. Maternal anxiety, risk factors and parenting in the first post-natal year. Child Care Health Dev 2014;41:314-323.

[3] Feldman R, Granat A, Pariene C, Kanety H, Kuint J, Gilboa-Schechtman E. Maternal depression and anxiety across the postpartum year and infant social engagement, fear regulation, and stress reactivity. J Am Acad Child Adolesc Psychiatry 2009;48: 919927.

[4] Dubois-Comtois K, Moss E, Cyr C, Pascuzzo K. Behaviour problems in middle childhood: the predictive role of maternal distress, child attachment, and mother-child interactions. J Abnorm Child Psychol 2013;41:1311-1324.

[5] Gravener JA, Rogosch FA, Oshri A, Narayan AJ, Cicchetti D, Toth SL. The relations among maternal depressive disorder, maternal Expressed Emotion, and toddler behavior problems and attachment. J Abnorm Child Psychol 2012;40:803-813.

[6] Murray L, Arteche A, Fearon P, Halligan S, Goodyer I, Cooper P. Maternal postnatal depression and the development of depression in offspring up to 16 years of age. $J \mathrm{Am}$ Acad Child Adolesc Psychiatry 2011;50:460-470.

[7] Halligan SL, Murray L, Martins C, Cooper PJ. Maternal depression and psychiatric outcomes in adolescent offspring: A 13-year longitudinal study. J Affect Disord 2007;97:145-154.

[8] Classens A, Engel M, Curran F. The effects of maternal depression on child outcomes during the first years of formal schooling. Early Child Res Q 2015;32:80-93. 
[9] Davis L, Edwards H, Mohay H, Wollin J. The impact of very premature birth on the psychological health of mothers. Early Hum Dev 2003;73:61-70.

[10] Mew AM, Holditch-Davis D, Belyea M, Miles FS, Fishel A. Correlates of depressive symptoms in mothers of preterm infants. Neonatal Netw 2003;22:51-60.

[11] Kong L, Cui Y, Qiu Y, Han S, Yu Z, Guo, X. Anxiety and depression in parents of sick neonates: A hospital-based study. J Clin Nurs 2013;22:1163-1172.

[12] Meijssen D, Wolf M, Koldewijn K, Baar A, Kok J. Maternal psychological distress in the first two years after very preterm birth and early intervention. Early Child Dev Care 2011;181:1-11.

[13] Doering LV, Moser DK, Dracup K. Correlates of anxiety, hostility, depression, and psychosocial adjustment in parents of NICU infants. Neonatal Netw 2000;19:15-23.

[14] Pinelli J. Effects of family coping and resources on family adjustment and parental stress in the acute phase of the NICU experience. Neonatal Netw 2000;19:27-37.

[15] McIntosh BJ, Stern M, Ferguson KS. Optimism, coping, and psychological distress: Maternal reactions to NICU hospitalization. Child Health Care 2004;33:59-76.

[16] Rowe L, Jones L. Discharge and beyond. A longitudinal study comparing stress and coping in parents of preterm infants. $J$ Neonatal Nurs 2010;16:258-266.

[17] Miles MS, Funk SG, Kasper MA. The neonatal intensive care unit environment: Sources of stress for parents. AACN Clin Issues Crit Care Nurs 1991;2:346-354.

[18] Barr P. A dyadic analysis of negative emotion personality predisposition effects with psychological distress in neonatal intensive care unit parents. Psycholog Trauma 2012;4:347-355.

[19] Miles MS, Funk S, Kasper MA. The stress response of mothers and fathers of preterm infants. Res Nurs Health 1991;15:261-269. 
[20] Franck L, Cox S, Allen A, Winter I. Measuring neonatal intensive care unit-related parental stress. J Adv Nurs 2005;49:608-615.

[21] Busse M, Stromgren K, Thorngate L, Thomas KA. Parent responses to stress: in the neonatal intensive care unit. Crit Care Nurs 2013;33:52-60.

[22] Shelton S, Meaney-Delman DM, Hunter M, Lee S. Depressive symptoms and the relationship of stress, sleep, and well-being among NICU mothers. J Nurs Educ Prac 2014;4:70-79.

[23] Alkozei A, McMahon E, Lahav A. Stress levels and depressive symptoms in NICU mothers in the early postpartum period. J Matern Fetal Med 2014;27:1738-1743.

[24] Farooqui A, Trajanovska M, Vinton C, Johnston L. Identification of parental stressors in the neonatal unit. 2006 Perinatal Society of Australia \& New Zealand 10th Annual Congress, Perth, Western Australia.

[25] Joseph RA, Mackley AB, Davis CG, Spear ML, Locke RG. Stress in fathers of surgical neonatal intensive care unit babies. Adv Neonatal Care 2007;7:321-325.

[26] Diffin J, Shields M, Cruise S, Johnston L.. Parents' experiences of caring for their infant following surgery in the neonatal period: A literature review. J Neonatal Nurs 2013;19:271-289.

[27] Bernier PL, Stefanescu A, Samoukovic G, Tchervenkov CI. The challenge of congenital heart disease worldwide: Epidemiologic and demographic facts. Semin Thorac Cardiovasc Surg Pediatr Card Surg Annu 2010;13:26-34.

[28] Leggat S. Childhood heart disease in Australa: Current practices and future needs. A report of HeartKids and Paediatric and Congenital Council of the Cardiac Society of Australia and New Zealand. (2011). Accessed 26/4/16: www.heartkids.org.au/wpcontent/uploads/2012/01/White_Paper_A4_March_2011_web_doc.pdf 
[29] Uzark K, Jones K. Parenting stress and children with congeital heart disease. J Pediatr Health Care 2003;17(4):163-168.

[30] Helfricht S, Latal B, Fischer JE, Tomaske M, Landolt MA. Surgery-related posttraumatic stress disorder in parents of children undergoing cardiopulmonary bypass surgery: a prospective cohort study. Pediatr Crit Care Med 2008;9:217-223.

[31] Lawoko S, Soares JJF. Psychosocial morbidity among parents of children with congenital heart disease: A prospective longitudinal study. Heart Lung 2006;35:301314.

[32] Franck LS, Mcquillan A, Wray J, Grocott MPW, Goldman A. Parent stress levels during children’s hospital recovery after congenital heart surgery. Pediatr Cardiol 2010;31:961-968.

[33] Doherty N, McCusker CG, Molloy B, Mulholland C, Rooney N, Craig B, et al. Predictors of psychological functioning in mothers and fathers of infants born with severe congenital heart disease. J Reprod Infant Psychol 2009;27:390-400.

[34] Fischer AL, Butz C, Nicholson L, Blankenship A, Dyke P, Cua CL. Caregiver anxiety upon discharge for neonates with congenital heart disease. Congenit Heart Dis 2012;7:41-45.

[35] Solberg Ø, Dale MT, Holmstrøm H, Eskedal, ET, Landolt MA, Vollrath, ME. Long term symptoms of depression and anxiety in mothers of infants with congenital heart defects. J Pediatr Psychol 2012;36:179-187.

[36] Dale M, Solberg Ø, Holmstrøm H, Landolt M, Eskeda L, Vollrath M.. Well-being in mothers of children with congenital heart defects: A 3-year follow-up. Qual Life Res 2012;22:2063-2072. 
[37] McCubbin HI, Patterson J. The family stress process: The Double ABCX model of adjustment and adaptation. Marriage and Family Review 1983;6:7-37.

[38] Zigmond AS, Snaith RP. The Hospital Anxiety and Depression scale. Acta Psychiatr Scand 1983;67:361-370.

[39] Endler NS, Parker JDA. Assessment of multidimensional coping: Task, emotion, and avoidance strategies. Psychol Assess 1994;6:50-60.

[40] Dunst CJ, Trivette CM, Deal AG. Enabling and empowering families: Principles and guidelines for practice. Cambridge, MA: Brookline Books 1988.

[41] Miles MS, Funk SG, Carlson J. Parental stressor scale: Neonatal intensive care unit. Nurs Res 1993;42:148-152.

[42] Scholz FW. The bootstrap small sample properties. University of Washington, Seattle, WA; 2007.

[43] Dabrowska A, Pisula E. Parenting stress and coping styles in mothers and fathers of preschool children with autism and Down syndrome. J Intellect Disabil Res 2010;54(3):266-280.

[44] Paster A, Brandwein D, Walsh J. A comparison of coping strategies used by parents of children with disabilities and parents of children without disabilities. Res Dev Disabil 2009;30(6):1337-1342.

[45] Heaman DJ. Perceived stressors and coping strategies of parents who have children with developmental disabilities: A comparison of fathers and mothers. J Pediatr Nurs 1995;10:311-320.

[46] Doucette J, Pinelli J. The effects of family resources, coping, and strains on family adjustment 18 to 24 months after the NICU experience. Adv Neonatal Care 2004;4(2):92-104. 
[47] Gale G, Franck LS, Kools S, Lynch M. Parents’ perceptions of their infant’s pain experience in the NICU. Int J Nurs Stud 2004;41:51-58.

[48] Schieman S, van Gundy K, Taylor J. Status, role, and resource explanations for age patterns in psychological distress. J Health Soc Behav 2001;42:80-96.

[49] Miech RA, Shanahan MJ. Socioeconomic status and depression over the life course. $J$ Health Soc Behav 2000;41:162-176. 


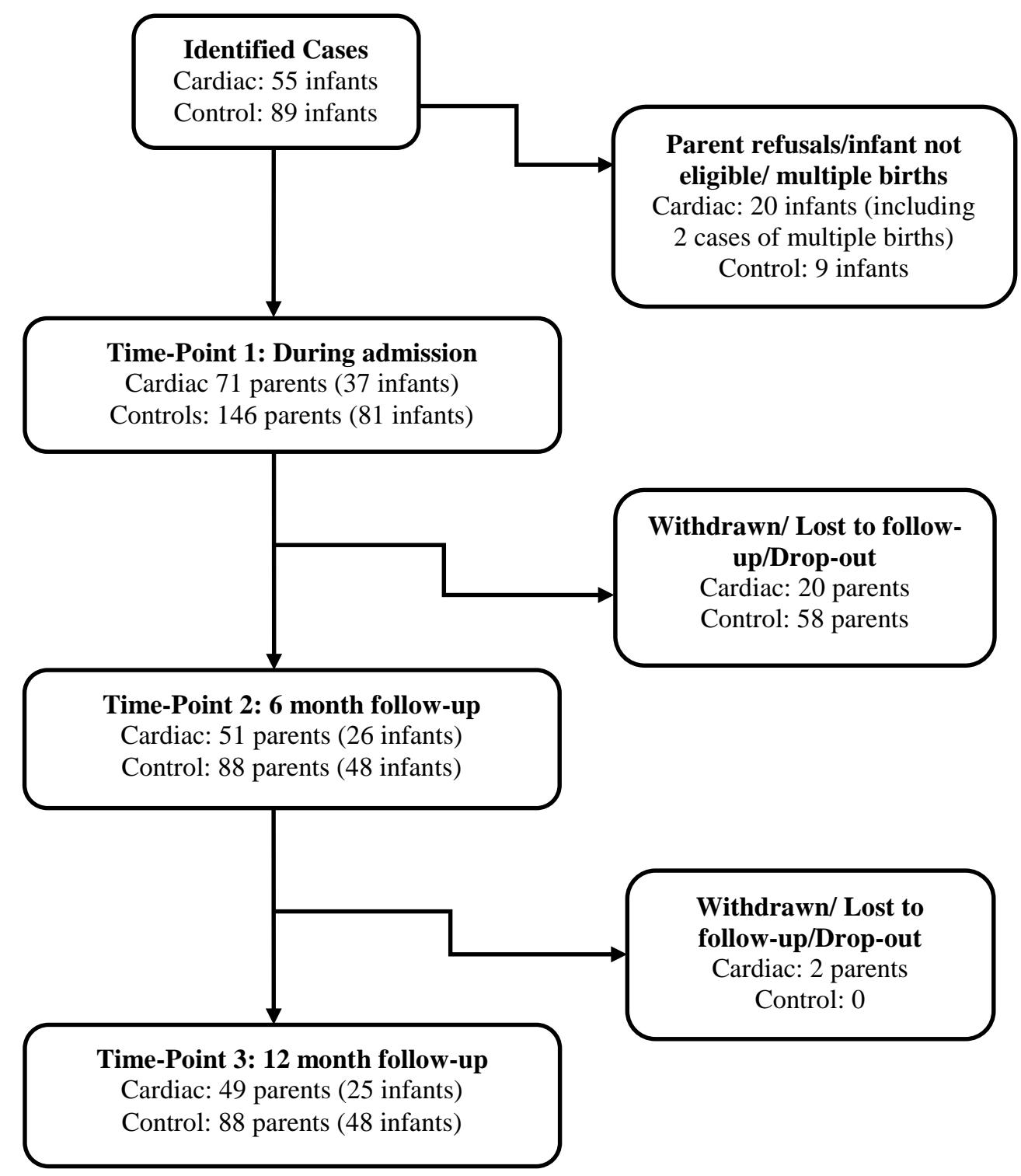

Figure 1: Overview of participants recruited to the study 
Table 1: Demographic Characteristics for Parents within the Cardiac and Control Groups at Time-Point 1

\begin{tabular}{lccc}
\hline \multicolumn{1}{c}{ Variable } & $\begin{array}{c}\text { Cardiac Group } \\
\mathbf{N = 7 1}\end{array}$ & $\begin{array}{c}\text { Control Group } \\
\mathbf{N = 1 4 6}\end{array}$ & $\boldsymbol{p}$ \\
\hline Parent N (\%) & & & 0.32 \\
Father & $34(47.9)$ & $66(45.2)$ & \\
Mother & $37(52.1)$ & $80(54.8)$ & \\
Parent Age (years) & & & \\
(Mean, SD) & & $32(6)$ & 0.48 \\
Male & $36(10)$ & $29(5)$ & 0.46 \\
Female & $30(5)$ & $117(80.1)$ & 0.10 \\
Married N (\%) & $52(73.2)$ & $72(49.3)$ & $<.02$ \\
First Child N (\%) & $45(63.4)$ & & \\
Education Level N (\%) & & $19(13.0)$ & \\
Higher School Certificate (HSC) & & & \\
University & $70(54.8)$ & \\
Cultural Identity N (\%) & $22(31.0)$ & & \\
Australian & & & \\
\hline
\end{tabular}


Table 2: Parents' mean (SD) scores on the Parental Stressor Scale:NICU

\begin{tabular}{|c|c|c|c|c|c|c|}
\hline \multirow[b]{2}{*}{ PSS:NICU Subscale } & \multicolumn{2}{|c|}{ Mothers (N=37) } & \multicolumn{2}{|c|}{ Fathers $(\mathrm{N}=34)$} & \multicolumn{2}{|c|}{ Comparison between groups* } \\
\hline & Mean (SD) & $95 \%$ CI & Mean (SD) & $95 \% \mathrm{CI}$ & $\mathbf{F}$ & $p$ \\
\hline Appearance \& Behaviour & $2.98(0.83)$ & $2.74-3.25$ & $2.86(0.90)$ & $2.56-3.20$ & 0.33 & 0.57 \\
\hline Sights \& Sounds & $2.61(0.65)$ & $2.40-2.82$ & $2.62(0.74)$ & $2.34-2.89$ & 0.001 & 0.98 \\
\hline Parental Role \& Relationship & $3.23(0.79)$ & $2.97-3.49$ & $2.64(0.78)$ & $2.35-2.89$ & 9.98 & 0.002 \\
\hline Overall Stress & $100.83(20.84)$ & $94.17-107.39$ & $92.38(27.07)$ & $83.47-102.06$ & 4.24 & 0.004 \\
\hline
\end{tabular}

MANOVA (Multivariate Analysis of Variance) to investigate any differences in scores between mothers and fathers 
Table 3: Mean (SD) scores of Depression and Anxiety over time for Mothers and Fathers within each group

\begin{tabular}{|c|c|c|c|c|c|c|c|c|c|c|c|c|c|c|}
\hline & \multicolumn{6}{|c|}{ Female } & \multicolumn{6}{|c|}{ Male } & \multicolumn{2}{|c|}{ Changes over time* } \\
\hline & \multicolumn{3}{|c|}{ Cardiac } & \multicolumn{3}{|c|}{ Control } & \multicolumn{3}{|c|}{ Cardiac } & \multicolumn{3}{|c|}{ Control } & \multirow[b]{2}{*}{$\mathbf{F}$} & \multirow[b]{2}{*}{$p$} \\
\hline & $\mathbf{N}$ & Mean (SD) & $95 \%$ CI & $\mathbf{N}$ & $\begin{array}{l}\text { Mean } \\
\text { (SD) }\end{array}$ & $95 \% \mathrm{CI}$ & $\mathbf{N}$ & Mean (SD) & $95 \% \mathrm{CI}$ & $\mathbf{N}$ & Mean (SD) & $95 \% \mathrm{CI}$ & & \\
\hline Depression & & & & & & & & & & & & & 2.42 & 0.09 \\
\hline Time-point 1 & 37 & 6.22 (4.89) & $4.71-8.43$ & 78 & 3.74 (3.08) & $2.75-4.50$ & 33 & $5.70(4.18)$ & $3.96-7.26$ & 64 & $2.83(2.24)$ & $2.29-3.71$ & & \\
\hline 6 months & 28 & $4.82(3.73)$ & $3.43-6.14$ & 50 & 4.12 (3.02) & $3.20-5.12$ & 25 & 3.56 (2.86) & $2.74-5.00$ & 40 & 3.60 (3.05) & $2.52-4.68$ & & \\
\hline 12 months & 28 & 3.82 (3.33) & $2.57-4.39$ & 46 & 3.83 (3.26) & $2.85-4.90$ & 24 & 4.88 (3.97) & $3.52-6.65$ & 38 & $\mathbf{3 . 8 0}(2.43)$ & $2.94-4.58$ & & \\
\hline Anxiety & & & & & & & & & & & & & 6.73 & 0.001 \\
\hline Time-point 1 & 37 & $9.57(4.16)$ & $8.29-11.43$ & 77 & $5.01(2.70)$ & $4.10-5.70$ & 33 & $8.91(4.08)$ & $7.35-10.22$ & 61 & 4.97 (2.89) & $3.97-5.87$ & & \\
\hline 6 months & 28 & 7.00 (4.09) & $5.57-8.50$ & 50 & $5.80(3.24)$ & $4.90-7.20$ & 25 & $\mathbf{6 . 6 0}(2.93)$ & $5.31-7.74$ & 40 & $5.18(3.10)$ & $3.94-5.97$ & & \\
\hline 12 months & 28 & $6.75(4.72)$ & $5.04-8.46$ & 46 & $5.28(3.36)$ & $4.05-6.38$ & 24 & 7.54 (3.27) & $6.17-9.00$ & 39 & $\mathbf{5 . 0 0}(3.27)$ & $4.03-6.16$ & & \\
\hline
\end{tabular}

* two-way repeated measures ANOVA to examine changes 
Table 4: Mean (SD) Scores for Coping Styles and Social Support, for Mothers and Fathers within each Group

\begin{tabular}{|c|c|c|c|c|c|c|c|c|c|c|c|c|}
\hline & \multicolumn{6}{|c|}{ Female } & \multicolumn{6}{|c|}{ Male } \\
\hline & \multicolumn{3}{|c|}{ Cardiac } & \multicolumn{3}{|c|}{ Control } & \multicolumn{3}{|c|}{ Cardiac } & \multicolumn{3}{|c|}{ Control } \\
\hline & $\mathbf{N}$ & $\begin{array}{c}\text { Mean } \\
\text { (SD) }\end{array}$ & $95 \%$ CI & $\mathbf{N}$ & Mean (SD) & $95 \%$ CI & $\mathbf{N}$ & Mean (SD) & $95 \%$ CI & $\mathbf{N}$ & Mean (SD) & $95 \% \mathrm{CI}$ \\
\hline \multicolumn{13}{|c|}{$\begin{array}{c}\text { Emotion-focused } \\
\text { Coping }\end{array}$} \\
\hline Time-point 1 & 36 & $\begin{array}{c}36.67 \\
(12.39)\end{array}$ & $33.96-40.75$ & 77 & $\begin{array}{c}37.07 \\
(13.63)\end{array}$ & $33.96-40.75$ & 33 & $\begin{array}{c}42.82 \\
(11.35)\end{array}$ & $38.53-47.88$ & 61 & $\begin{array}{c}38.89 \\
(12.21)\end{array}$ & $33.64-42.33$ \\
\hline 12 months & 27 & $\begin{array}{c}\mathbf{4 1 . 8 9} \\
(13.22)\end{array}$ & $35.54-43.58$ & 48 & $\begin{array}{c}37.02 \\
(12.56)\end{array}$ & $35.54-43.58$ & 23 & $\begin{array}{c}42.70 \\
(11.86)\end{array}$ & $36.06-47.53$ & 40 & $\begin{array}{c}38.65 \\
(12.00)\end{array}$ & $34.27-42.87$ \\
\hline \multicolumn{13}{|l|}{$\begin{array}{l}\text { Task-focused } \\
\text { Coping }\end{array}$} \\
\hline Time-point 1 & 37 & $\begin{array}{l}\mathbf{5 6 . 9 5} \\
(8.86)\end{array}$ & $53.08-60.29$ & 75 & $\begin{array}{c}\mathbf{5 9 . 5 1} \\
(13.44)\end{array}$ & $53.08-60.29$ & 34 & $\begin{array}{c}\mathbf{5 1 . 1 2} \\
(12.31)\end{array}$ & $50.77-57.53$ & 63 & $\begin{array}{c}56.43 \\
(12.64)\end{array}$ & $51.38-60.50$ \\
\hline 12 months & 27 & $\begin{array}{l}54.93 \\
(9.42)\end{array}$ & $51.38-59.04$ & 48 & $\begin{array}{c}\mathbf{5 7 . 8 1} \\
(14.16)\end{array}$ & $51.38-59.04$ & 22 & $\begin{array}{c}\mathbf{5 4 . 6 4} \\
(7.510)\end{array}$ & $52.65-58.41$ & 40 & $\begin{array}{c}\mathbf{5 7 . 4 8} \\
(13.08)\end{array}$ & $52.43-62.13$ \\
\hline \multicolumn{13}{|c|}{ Avoidance Coping } \\
\hline Time-Point 1 & 37 & $\begin{array}{c}42.46 \\
(10.29)\end{array}$ & $37.38-45.75$ & 77 & $\begin{array}{c}\mathbf{4 7 . 1 2} \\
(12.36)\end{array}$ & $37.38-45.75$ & 32 & $\begin{array}{c}\mathbf{4 1 . 6 3} \\
(10.34)\end{array}$ & $34.77-44.76$ & 61 & $\begin{array}{c}47.85 \\
(10.03)\end{array}$ & $42.80-48.63$ \\
\hline 12 months & 27 & $\begin{array}{l}41.11 \\
(8.75)\end{array}$ & $38.83-45.29$ & 48 & $\begin{array}{c}\mathbf{4 5 . 0 0} \\
(10.28)\end{array}$ & $38.83-45.29$ & 24 & $\begin{array}{c}\mathbf{4 1 . 0 8} \\
(11.22)\end{array}$ & $36.59-46.35$ & 40 & $\begin{array}{c}44.38 \\
(11.00)\end{array}$ & $39.67-47.80$ \\
\hline \multicolumn{13}{|l|}{ Social Support } \\
\hline Time-point 1 & 37 & $\begin{array}{l}33.78 \\
(9.40)\end{array}$ & $28.96-36.67$ & 74 & $\begin{array}{c}33.92 \\
(12.71)\end{array}$ & $30.26-38.77$ & 33 & $\begin{array}{c}37.09 \\
(11.66)\end{array}$ & $30.06-41.00$ & 63 & $\begin{array}{c}35.83 \\
(11.86)\end{array}$ & $30.40-37.33$ \\
\hline 6 months & 28 & $\begin{array}{l}34.36 \\
(9.47)\end{array}$ & $30.00-38.29$ & 46 & $\begin{array}{c}31.15 \\
(11.28)\end{array}$ & $26.83-35.23$ & 24 & $\begin{array}{c}37.46 \\
(13.27)\end{array}$ & $30.89-43.88$ & 39 & $\begin{array}{c}31.62 \\
(11.26)\end{array}$ & $27.04-34.73$ \\
\hline 12 months & 27 & $\begin{array}{c}33.19 \\
(10.15)\end{array}$ & $28.29-35.83$ & 48 & $\begin{array}{c}29.13 \\
(12.13)\end{array}$ & $27.63-35.46$ & 24 & $\begin{array}{c}37.50 \\
(12.34)\end{array}$ & $29.24-41.18$ & 39 & $\begin{array}{c}30.38 \\
(12.48)\end{array}$ & $27.20-36.26$ \\
\hline
\end{tabular}


Supplemental File 1: Infant Cardiac Conditions

\begin{tabular}{|c|c|c|}
\hline Primary cardiac condition & $\mathbf{N}$ & $\%$ \\
\hline Transposition of the great arteries & 12 & 32.4 \\
\hline Hypoplastic left heart syndrome & 5 & 13.5 \\
\hline Coarctation of aorta & 9 & 24.3 \\
\hline
\end{tabular}

\section{Complex cardiac conditions}

1

- Fallots

1

2.7

- Total anomalous pulmonary venous

1

2.7

- $\quad$ Truncus arteriosus

- Atrial septic defect

- Aortic arch

- Interrupted aortic arch

- Pulmonary atresia

- Complex congenital heart disease 
Supplemental File 2: Categories of anxiety and depression for parents within each group

\begin{tabular}{|c|c|c|c|c|}
\hline & \multicolumn{2}{|c|}{ Mothers } & \multicolumn{2}{|c|}{ Fathers } \\
\hline & $\begin{array}{c}\text { Cardiac } \\
\text { Cohort N (\%) }\end{array}$ & $\begin{array}{c}\text { Control } \\
\text { Cohort N (\%) }\end{array}$ & $\begin{array}{c}\text { Cardiac } \\
\text { Cohort N (\%) }\end{array}$ & $\begin{array}{c}\text { Control } \\
\text { Cohort N (\%) }\end{array}$ \\
\hline Time-Point 1 & $\mathrm{~N}=37$ & $\mathrm{~N}=\mathbf{8 0}$ & $\mathrm{N}=66$ & $N=34$ \\
\hline \multicolumn{5}{|l|}{ Anxiety } \\
\hline Normal & 14 (37.8) & 65 (81.3) & $11(32.4)$ & $50(75.8)$ \\
\hline Mild & $9(24.3)$ & $8(10.0)$ & $10(29.4)$ & 8 (12.1) \\
\hline Moderate & $10(27.0)$ & $4(5.0)$ & $10(29.4)$ & $3(4.5)$ \\
\hline Severe & $4(10.8)$ & 0 & $2(5.9)$ & 0 \\
\hline \multicolumn{5}{|l|}{ Depression } \\
\hline Normal & 26 (70.3) & 71 (80.8) & 21 (61.8) & 63 (95.1) \\
\hline Mild & $3(80.1)$ & $2(2.5)$ & $7(20.6)$ & $1(1.5)$ \\
\hline Moderate & $4(10.8)$ & $5(6.3)$ & $4(11.8)$ & 0 \\
\hline Severe & $4(10.8)$ & 0 & $1(2.9)$ & 0 \\
\hline 6 months & $\mathrm{N}=28$ & $N=48$ & $\mathrm{~N}=25$ & $\mathrm{~N}=41$ \\
\hline \multicolumn{5}{|l|}{ Anxiety } \\
\hline Normal & 17 (60.7) & 38 (79.2) & $16(64.0)$ & $29(70.7)$ \\
\hline Mild & $4(14.3)$ & 4 (8.3) & $6(24.0)$ & 8 (19.5) \\
\hline Moderate & $7(25.0)$ & $5(10.4)$ & $3(12.0)$ & $3(7.3)$ \\
\hline Severe & 0 & $1(2.1)$ & 0 & 0 \\
\hline \multicolumn{5}{|l|}{ Depression } \\
\hline Normal & $21(75)$ & 42 (87.5) & 23 (92) & 35 (85.4) \\
\hline Mild & $4(14.3)$ & $3(6.3)$ & $1(4.0)$ & $4(9.8)$ \\
\hline Moderate & 3 (10.7) & 3 (6.3) & $1(4.0)$ & $1(2.4)$ \\
\hline Severe & 0 & 0 & 0 & 0 \\
\hline 12 months & $\mathrm{N}=28$ & $\mathrm{~N}=48$ & $\mathrm{~N}=24$ & $\mathrm{~N}=40$ \\
\hline \multicolumn{5}{|l|}{ Anxiety } \\
\hline Normal & 18 (64.3) & 35 (72.9) & $11(45.8)$ & $30(75.0)$ \\
\hline Mild & $3(10.7)$ & $4(8.3)$ & $8(33.3)$ & $4(10.0)$ \\
\hline Moderate & 3 (10.7) & $7(14.6)$ & 3 (12.5) & $4(10.0)$ \\
\hline Severe & 4 (14.3) & 0 & $1(4.2)$ & $1(2.5)$ \\
\hline \multicolumn{5}{|l|}{ Depression } \\
\hline Normal & 23(82.1) & 38 (79.2) & $18(75.0)$ & 33 (82.5) \\
\hline Mild & 5 (17.9) & $5(10.4)$ & $2(8.3)$ & $4(10.0)$ \\
\hline Moderate & 0 & $1(2.1)$ & 3 (12.5) & $1(2.5)$ \\
\hline Severe & 0 & $1(2.1)$ & 0 & 0 \\
\hline
\end{tabular}


Supplemental File 3: Pearson's correlation matrix illustrating the variables associated with parental anxiety and depression during their infants' admission to the NICU for cardiac surgery

\begin{tabular}{|c|c|c|c|c|c|c|c|c|c|}
\hline & & \multicolumn{3}{|c|}{$\begin{array}{c}\text { Parental Stressor Scale:NICU (PSS:NICU) } \\
\text { subscales }\end{array}$} & \multicolumn{3}{|c|}{$\begin{array}{l}\text { Coping Inventory for Stressful Situations (CISS) } \\
\text { Subscales }\end{array}$} & \multirow{2}{*}{$\begin{array}{l}\text { Family Support } \\
\text { Scale (FSS) } \\
\text { Social Support }\end{array}$} & \multirow[b]{2}{*}{$\begin{array}{l}\text { Parental } \\
\text { age }\end{array}$} \\
\hline & & $\begin{array}{l}\text { Appearance } \\
\text { \& Behaviour }\end{array}$ & $\begin{array}{l}\text { Sights \& } \\
\text { Sounds }\end{array}$ & $\begin{array}{l}\text { Parental Role } \\
\text { \& Relationship }\end{array}$ & $\begin{array}{l}\text { Emotion- } \\
\text { focused }\end{array}$ & Task-focused & Avoidance & & \\
\hline $\begin{array}{l}\text { Hospital } \\
\text { Anxiety and }\end{array}$ & Anxiety & $.310^{*}$ & $.401 * * *$ & .223 & .069 & $-.247 *$ & -.040 & .096 & .062 \\
\hline $\begin{array}{l}\text { Depression } \\
\text { Scale (HADS) }\end{array}$ & Depression & $.260^{*}$ & $.269 *$ & .145 & .140 & .006 & -.082 & -.031 & .115 \\
\hline
\end{tabular}

